\title{
Immunohistochemical Study of S-100 Protein in the Bovine Lymph Node and Spleen
}

\author{
By \\ Yasuro ATOJI and Yoshitaka SUZUKI \\ Department of Veterinary Anatomy, Faculty of Agriculture, \\ Gifu University, Gifu 501-11, Japan \\ -Received for Publication, March 28, 1990-
}

\begin{abstract}
Key words: Endothelial cell, Blood vessel, Lymph vessel, S-100 protein, Cow
Summary: Immunohistochemistry using anti-bovine S-100 protein serum was examined in the bovine lymph node and spleen. In the lymph node, immunoreactivity was found in endothelial cells of lymph vessels and in endothelial and reticular cells of the sinuses. In the spleen, immunoreactivity was observed in endothelial cells of the trabecular artery, central artery, penicillar artery, sheathed artery, terminal capillary, trabecular vein and lymph vessel. In addition, the follicular dendritic cells in germinal centers both of the lymph node and spleen were stained with S-100 protein. These findings suggest that S-100 protein of the vascular systems may be related to the flow of lymph and blood.
\end{abstract}

S-100 protein was first extracted from vertebrate brains and peripheral nerves and consists of dimer of $\alpha \alpha, \alpha \beta$ and $\beta \beta$ subunits (Moore, 1965; Calissano et al., 1969; Donato, 1986). S-100 protein was initially considered to be a unique $\mathrm{Ca}^{2+}$-binding protein in astrocytes, oligodendrocytes and Schwann cells of the nervous system. However, immunohistochemical studies have recently demonstrated S-100 protein in many cell types of non-nervous tissues of various mammalian species. In lymphoid tissues, S-100 protein was restricted in non-lymphoid cells; the follicular dendritic cells (Iwanaga et al., 1982; Cocchia et al., 1983; Haimoto et al., 1987; Suigmura et al., 1987), interdigitating cells (Pelletier et al., 1986; Haimoto et al., 1987; Sugimura et al., 1987) and tingible body macrophages (Takahashi et al., 1984; Sugimura et al., 1987). However, species difference of S-100 immunoreactivity is confirmed in non-lymphoid cell types of animals examined. This is probably due to usage of anti-bovine serum in the immunostaining procedure ignoring the species. In fact, species difference of amino acid sequences and amount of two subunits of S-100 protein has been demonstrated (Manabe et al., 1982; Kuwano et al., 1984; Baudier et al., 1985; Jensen et al., 1985). Therefore, the immunoreactivity of anti-bovine serum in lymphoid organs of the proper species must be examined. The present paper reports the distribution of S-100 immunoreactive cells in the bovine lymph node and spleen.

\section{Materials and Methods}

Hepatic and superficial inguinal lymph nodes and spleens were removed from cows (Holstein strain) in a local slaughterhouse and immediately fixed with $10 \%$ formalin. Paraffin sections at $4 \mu \mathrm{m}$ in thickness were immunostained with $\mathrm{S}-100$ antiserum by the peroxidaseantiperoxidase (PAP) and indirect methods. Sections were preincubated with $1 \%$ normal goat serum and then incubated with polyclonal bovine S-100 rabbit antiserum (Dakopatts, 1:500) or monoclonal bovine S-100 $\alpha$ and $\beta$ mouse antiserum (Japan Immunoresearch Laboratories, 1:100) overnight at $4^{\circ} \mathrm{C}$. After rinsing in $0.01 \mathrm{M}$ phosphate-buffered saline (PBS), they were treated with rabbit IgG goat antiserum (Tago Inc., 1:100) followed by incubation with PAP complex (Cappel Inc., 1:500) or peroxidase-labeled anti-mouse IgG (Tago Inc., 1:100), respectively, for $30 \mathrm{~min}$ at room temperature. Reaction product was visualized by 3,3'diaminobenzidine $(25 \mathrm{mg} / 100 \mathrm{ml})$ and $0.003 \% \quad \mathrm{H}_{2} \mathrm{O}_{2}$ for $10 \mathrm{~min}$. Some sections were slightly counterstained with hematoxylin. Control sections were incubated with non-immunized serum substituting for the primary antiserum or preabsorbed S-100 antiserum by excessive concentration $(0.1 \mathrm{mg} / \mathrm{ml})$ of bovine $\mathrm{S}-100$ protein (Sigma) in advance. 


\section{Results}

In the lymph node, S-100 immunoreactivity found in endothelial cells of the afferent lymph vessel, marginal sinus, intermediate sinus, medullary sinus and efferent lymph vessel (Figs. 1, 2, 4, 5). These cells reacted with $\alpha$ monoclonal antibody (Fig. 3). Endothelial cells lining cortical surface on the marginal sinus showed less immunostaining than those of the capsular side (Fig. 1). Reticular cells bridging the sinus (Figs. 1, $2,4)$ and the follicular dendritic cells in germinal centers (Fig. 6) were also stained with S-100 protein. Endothelial cells of arteries and lymph vessels in the trabeculae showed S-100 protein, but not in the vein. Endothelial cells of arteries and capillaries in medullary cords were positive for S-100 protein. Some macrophages in the sinus were immunoreactive.

In the spleen, the immunostaining was observed in endothelial cells of the trabecular artery, central artery, penicillar artery, sheathed artery, terminal capillary and trabecular vein (Figs. 7, 8, 9, 10). They were stained with $\beta$ monoclonal antibody. Endothelial cells of venous sinuses and pulp veins were negative. Endothelial cells of lymph vessels in the trabeculae (Fig. 7) and the follicular dendritic cells in germinal centers (Fig. 8) also showed S-100 protein.

\section{Discussion}

The present study elucidated the distribution of S-100 protein immunoreactive cells of the bovine lymph node and spleen using anti-bovine $\mathrm{S}-100$ protein serum. This evidence indicates typical presence of S-100 protein in the immune system, since the species difference of the antigenicity is apparently ruled out. Several studies have revealed S-100 immunoreactive cell types in the lymph node and spleen of some species: the follicular dendritic cells, interdigitating cells or macrophages (Iwanaga et al., 1982; Vanstapel et al., 1986; Haimoto et al., 1987; Sugimura et al., 1987). In these studies, cell population of S-100 immunoreactivity tends to predominate in the germinal center and paracortical area. However, the present study showed another major population of $\mathrm{S}-100$ positive cells in the vascular system of the lymph node and spleen.

Immunohistochemical demonstration of S-100 protein has been made in endothelial cells of arteries, capillaries or lymph nodes in human (Vanstapel et al., 1986; Haimoto et al., 1987), cattle (Iwanaga et al., 1987; Kamiya et al., 1989) and pig (Iwanaga et al., 1987). However, the description of distribution of S-100 positive endothelial cells in various organs is fragmentary. The present study demonstrated that endothelial cells and reticular cells along the lymph flow from the afferent lymph vessels to efferent lymph vessels were S-100 immunoreactive. Localization of $\alpha$ subunit in these cells is in partial agreement with the study of Haimoto et al. (1987). In spleen, the present study also revealed the immunoreactivity of S-100 protein in endothelial cells of the trabecular artery, central artery, penicillar artery, sheathed artery, terminal capillary and trabecular vein. They were stained for $\beta$ subunit in the monoclonal staining. It is consistent with the study of Iwanaga et al. (1987). These findings suggest that endothelial cells of the blood and lymph vascular systems share different subunits of S-100 protein. Iwanaga et al. (1987) reported no immunoreactivity of S-100 protein in endothelial cells of veins in the tongue, stomach, small intestine, liver, pancreas, kidney and lymph node of the cattle and pig, but the spleen had not been examined in their study. In the spleen of the present study, endothelial cells reacted with S-100 protein in the trabecular vein, but not in the venous sinus or the pulp vein. This might be dependent on regional differences in the blood flow.

The function of S-100 protein both in the vascular and immune systems remains to be established. Simonian et al. (1989) found that the bovine S-100 protein stimulates ATPase activity. ATPase has been histochemically shown to be located in endothelial cells of the artery (Borgers et al., 1971; Ogawa et al., 1986), capillary (Githens, 1983; Mata and Fink, 1989) and lymph vessel (Casley-Smith, 1967; Schneider and Thury, 1973). In the immune system, S-100 positive cell types have ATPase activity: Langerhans cells (SilerbergSinakin, 1980; Cocchia et al., 1981; Austyn, 1987), follicular dendritic cells and tingible body macrophages (Eikelenboom, 1978; Vanstapel et al., 1986; Haimoto et al., 1987; Sugimura et al., 1987). These evidence suggests a possibility that S-100 protein of endothelial cells and follicular dendritic cells is involved in the function of ATPase activity.

On the other hand, it is not reasonable to consider a same role of S-100 protein in endothelial cells and follicular dendritic cells only from an evidence of immunostaining. Iwanaga et al. (1987) speculated that S-100 protein of endothelial cells plays a role in transcytosis of fatty acid from the blood. In the lymph node, the continuity of S-100 positive endothelial cells of lymph vessels would serve to prevent perfusion of foreign bodies from lymph to perivascular space and to drain lymph into the follicles where follicular dendritic cells act as antigen presenting cells. This is also thought to be case for endothelial cells of the spleen.

\section{Acknowledgements}

The present study was supported in part by a Grantin-Aid for Scientific Research (63480090) from the Ministry of Education, Science and Culture, Japan. 


\section{References}

1) Austyn, J. M.: Lymphoid dendritic cells. Immunology, 62 161-170, 1987

2) Baudier, J., Labourdette, G. and Gerard, D.: Rat brain S100b protein: purification, characterization, and ion binding properties. A comparison with bovine $\mathrm{S} 100 \mathrm{~b}$ protein. J. Neurochem., 44: 76-84, 1985.

3) Borgers, M., Schaper, J. and Schaper, W.: Localization of specific phosphatase activities in canine coronary blood vessels and heart muscle. J. Histochem. Cytochem., 19: 526-539, 1971.

4) Calissano, P., Moore, B. W. and Friesen, A.: Effect of calcium ion on S-100, a protein of the nervous system. Biochemistry, 4: 4318-4326, 1969.

5) Casley-Smith, J. R.: The fine structure, properties and permeabilities of the lymphatic endothelium. Experientia (Suppl.), 14: 19-39, 1967.

6) Cocchia, D., Michetti, F. and Donato, R.: Immunochemical and immunocytochemical localization of S-100 antigen in normal human skin. Nature, 294: 85-87, 1981.

7) Cocchia, D., Tiberio, G., Santarelli, R. and Michetti, F.: S-100 protein in "follicular dendritic" cells of rat lymphoid organs. Cell Tissue Res., 230: 95-103, 1983.

8) Donato, R.: S-100 proteins. Cell Calcium, 7: 123-145, 1986.

9) Eikelenboom, P.: Dendritic cells in the rat spleen follicles. A combined immuno- and enzyme histochemical study. Cell Tissue Res., 190: 79-87, 1978.

10) Githens, S.: Localization of alkaline phosphatase and adenosine triphosphatase in the mammalian pancreas. J. Histochem. Cytochem., 31: 697-705, 1983.

11) Haimoto, H., Hosoda, S. and Kato, K.: Differential distribution of immunoreactive $\mathrm{S} 100-\alpha$ and $\mathrm{S} 100-\beta$ proteins in normal nonnervous human tissues. Lab. Invest., 57: 489-498, 1987.

12) Iwanaga, T., Fujita, T., Masuda, T. and Takahashi, Y.: S-100 protein immunoreactive cells in the lymph node and spleen of the rat. Arch. Histol. Jap., 45: 393-397, 1982.

13) Iwanaga, T., Fujita, T., Takahashi, Y. and Isobe, T.: Immunohistochemical demonstration of S-100 protein in the endothelial cells of blood vessels in the pig and cattle. Biomed. Res., 8: 329-334, 1987.

14) Jensen, R., Marshak, D. R., Anderson, C., Lukas, T. J. and Watterson, D. M.: Characterization of human brain S100 protein fraction: amino acid sequence of S-100 $\beta$. J. Neurochem., 45: 700-705, 1985

15) Kamiya, S., Tsukushi, M., Yamano, S. and Daigo, M.: S-100 protein immunoreactive cells in the bovine ovary. Anat. Rec.,
223: 384-386, 1989.

16) Kuwano, R., Usui, H., Maeda, T., Fukui, T., Yamanari, N., Ohtsuka, E., Ikehara, M. and Takahashi, Y.: Molecular cloning and the complete nucleotide sequence of CDNA to m RNA for S-100 protein of rat brain. Nucleic Acids Res., 12 7455-7465, 1984.

17) Manabe, T., Jitzukawa, S., Ishioka, N., Isobe, T. and Okuyama, T.: Separation of extremely acidic proteins, S-100 proteins and calmodulin, in some bovine tissues and mammalian brains by two-dimensional electrophoresis in the absence of denaturing agents. J. Biochem., 91: 1009-1015, 1982.

18) Mata, M. and Fink, D. J.: $\mathrm{Ca}^{++}$-ATPase in the central nervous system: an EM cytochemical study. J. Histochem. Cytochem., 37: 971-980, 1989.

19) Moore, B. W.: A soluble protein characteristic of the nervous system. Biochem. Biophys. Res. Commun., 19: 739-744, 1965.

20) Ogawa, K., Fujimoto, K. and Ogawa, K.: Ultracytochemical studies of adenosine nucleotidases in aortic endothelial and smooth muscles - $\mathrm{Ca}^{++}$-ATPase and $\mathrm{Na}^{+}, \mathrm{K}^{+}$-ATPase Acta Histochem. Cytochem., 19: 601-620, 1986.

21) Pelletier, M., Tauta, C., Landry, D., Montplaisir, S., Chartrand, C. and Perreault, C.: Characterization of human thymic dendritic cells in culture. Immunology, 58: 263-270, 1986.

22) Schneider, I. and Thury, G.: The histochemistry of prefascial lymph vessels in recurrent erysipelas. Angiologica, 10: 142-151, 1973.

23) Silberberg-Sinakin, I., Gigli, I., Baer, R. L. and Thorbecke, G. J.: Langerhans cells: role in contact hypersensitivity and relationship to lymphoid dendritic cells and to macrophages. Immunol. Rev., 53: 203-232, 1980.

24) Simonian, A., Baudier, J. and Haglid, K. G.: Modulation of ATPase activities in the central nervous system by the S-100 proteins. Neurochem. Res., 14: 761-764, 1989.

25) Sugimura, M., Ishimaru, H., Atoji, Y. and Suzuki, Y.: S-100 protein $\alpha$ subunit immunoreactivity of follicular dendritic cells in germinal centers of canine and caprine lymph nodes. Jpn. J. Vet. Sci., 49: 1183-1185, 1987.

26) Takahashi, K., Isobe, T., Ohtsuki, Y., Akagi, T., Sonobe, H. and Okuyama, T.: Immunohistochemical study on the distribution of $\alpha$ and $\beta$ subunits of $\mathrm{S}-100$ protein in human neoplasm and normal tissues. Virchows Arch. B, 45: 385-396, 1984.

27) Vanstapel, M. J., Gatter, K. C., Wolf-Peeters, C., Mason, D. Y. and Desmet, V. D.: New sites of human S-100 immunoreactivity detected with monoclonal antibodies. Am. J. Clin. Pathol., 85: 160-168, 1986. 
Plate I
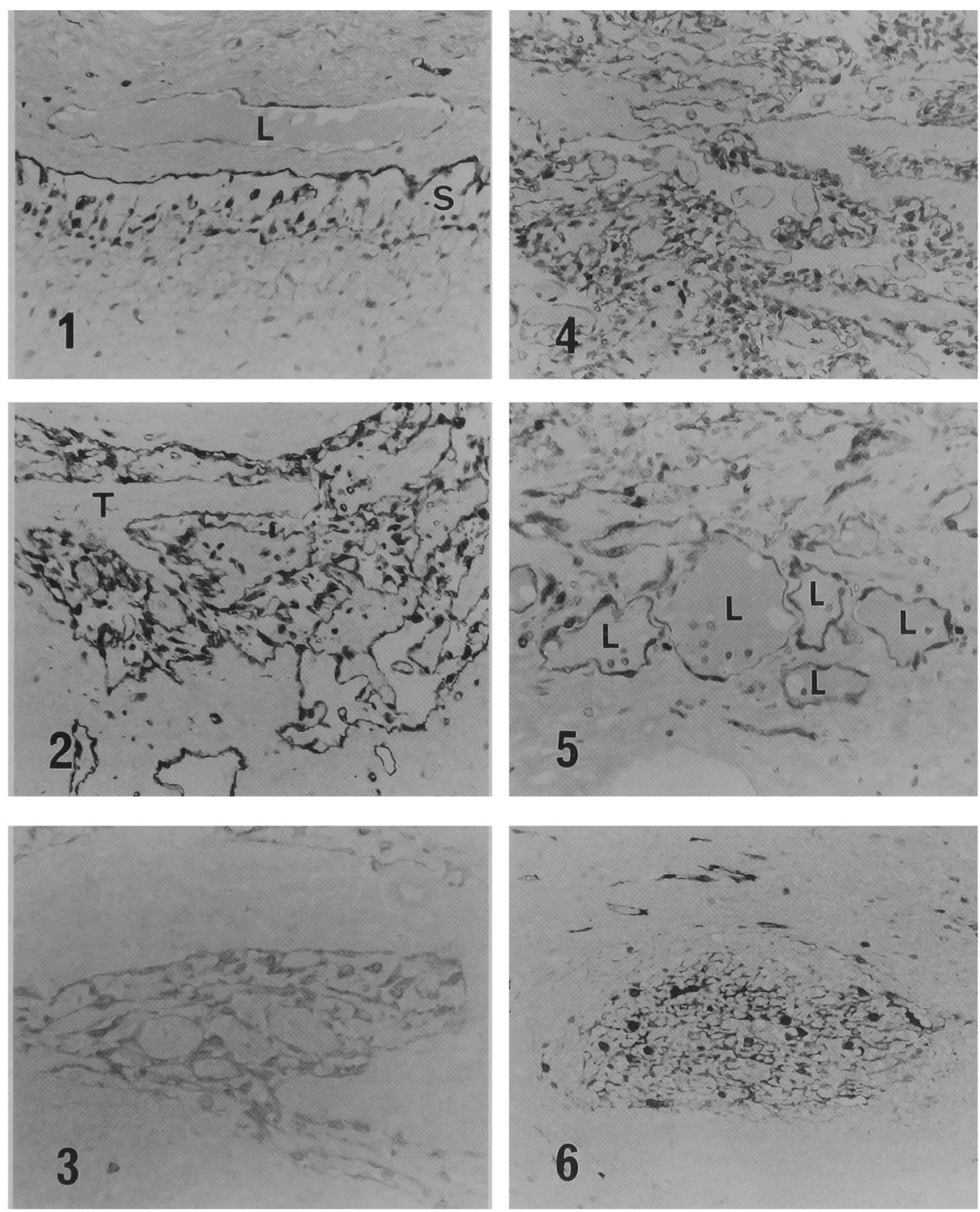

\section{Explanation of Figures}

\section{Plate I}

Fig. 1. S-100 immunoreactivity is seen in endothelial cells of an afferent lymph vessel (L) and a marginal sinus (S). $\times 170$.

Fig. 2. S-100 immunostaining in the intermediate sinuses. T: trabecula. $\times 150$.

Fig. 3. Endothelial cells and reticular cells of the intermediate sinuses are stained with $\alpha$ monoclonal antibody. $\times 230$.

Fig. 4. S-100 immunostaining in a medulla. $\times 150$.

Fig. 5. Efferent lymph vessels (L) in a hilus are stained with S-100 protein. Hematoxylin after PAP staining. $\times 230$.

Fig. 6. Follicular dendritic cells in a germinal center. $\times 150$. 
Plate II
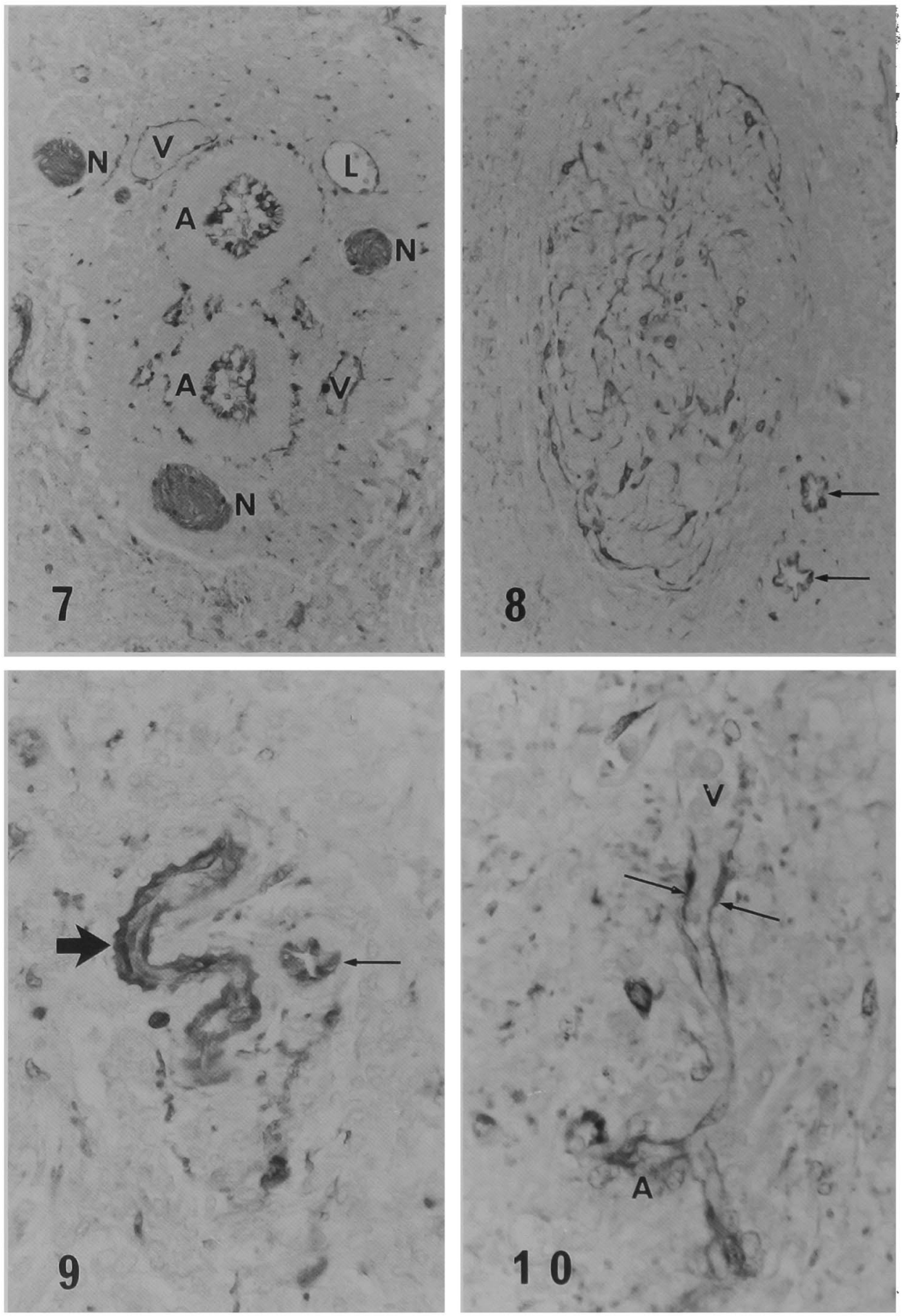

\section{Plate II}

Fig. 7. Trabecula in the spleen. Endothelial cells of arteries (A), veins (V) and lymph vessel (L) are positive. N: nerve fibers. $\times 210$.

Fig. 8. Endothelial cells of two central arteries (arrows) and follicular dendritic cells of a germinal center show S-100 immunoreactive. $\times 220$.

Fig. 9. Endothelial cells of penicillar arteries are positive. Thin arrow: transverse section of the artery, thick arrow: longitudinal section of the artery. $\times 550$.

Fig. 10. Terminal capillary from a sheathed artery (A) opens a venous sinus (V). Endothelial cells (arrows) of a capillary are apparently positive for S-100 protein. $\times 640$. 